\title{
Improvement of power supply reliability by means of remote control of the automatic repeated switching-on of sectionalizing circuit-breakers
}

\author{
I. Fomin ${ }^{1, *}, R$. Belikov $^{1}, V$. Zelyukin $^{1}$, and E.V. Mikhailova ${ }^{2}$ \\ ${ }^{1}$ Orel State Agrarian University named after N.V. Parakhin, Orel, Russia \\ ${ }^{2}$ Kazan State Power Engineering University, Kazan, Russia
}

\begin{abstract}
An important direction in improving the technical and economic level of technologies and agricultural production machinery is to ensure high reliability of power supply. Power interruptions cause damage to both agricultural consumers and power supply organizations. Therefore, obtaining on-line information about the occurrence of emergency operating conditions, and, therefore, minimizing the time for making operational decisions on their elimination, is an urgent task. Known methods and technical control means are complex, expensive and not effective enough. At the same time, they have both advantages and disadvantages. In this respect, it is very important to work out efficient technical means of remote control of power line sectionalizing circuit-breakers of the agro-industrial complex on the basis of innovative methods of monitoring. The proposed control method is implemented in a device for remote control of the overhead line circuit-breaker operation based on an analog-to-digital converter, with subsequent software-based processing of the received data on a computer. This method implementation of circuit breaker opening remote control will improve power supply reliability of agricultural consumers.
\end{abstract}

\section{Introduction}

A distinguishing feature of distribution networks is inadequate equipment by switching devices. If in the main networks of high and ultrahigh voltage almost any load node is equipped with switching devices, so that by operating them, this node can be separated from the main power supply and switched to the stand-by one, then on the $10 \mathrm{kV}$ line most often only a few disconnecting switches are installed. Therefore, if any line section is damaged, all connected consumers will be disconnected for a long time. In order to improve power supply reliability of consumers of the agro-industrial complex, long-distance power lines are sectionalized. In normal operation mode, the sectionalizing circuit breakers are switched on and trip in case a short circuit occurs in the line behind the point of their installation. After tripping, if the circuit breaker is equipped with an automatic reclosing device, it is switched on again [1]. The proportion of unstable damage is very high and amounts to $50-80 \%$ on overhead lines of different voltage. In case of sustained outages, the dispatchers of each enterprise are interested in obtaining quick information for making operational decisions on damage elimination.

\section{Theoretical research}

Studies of different authors [2-6] made it possible to reveal signs that allow remote control of the operation results of the distribution network circuit-breakers. The analysis of statistical data on changes in current rush during typical time intervals gave a complete visual picture of the occurring processes and was the initial necessary material for the development of remote control methods. On the basis of the physical processes of circuit-breaker opening, new methods for remote control of automatic reclosing of sectionalizing circuit-breakers $[7,8]$ were developed.

When fixing the appearance of a short-circuit current rush at the beginning of a sectionalized line caused by short circuit in the line [9], the time counting, equal to the time of protection operation of each circuit breaker installed in the sectionalized line is started; and at the same time the moment of the short-circuit current rush opening is controlled. And if the moment of the end of the time counting of the protection operation of one of the circuit breakers and the moment of the short-circuit current rush opening coincide, then the opened circuit breaker is determined. Further, from the moment of opening of the first short-circuit current rush, time counting that is equal to the holding time of the automatic reclosing of the opened circuit-breaker is started.

With the appearance of the second current rush, at the moment of the end of the time counting of the automatic reclosing holding time of this circuit-breaker, it is greater than the normal operating current, but less than the short-circuit current, meanwhile the fact of successful automatic reclosing of the sectionalizing

\footnotetext{
* Corresponding author: finigor@rambler.ru
} 
circuit-breaker is established [10]; and if it is greater than or equal to the short-circuit current, the unsuccessful automatic reclosing of a sectionalizing circuit-breaker of a sectionalized transmission line is established [11,12]. To implement the control of successful and unsuccessful automatic reclosing of sectionalizing circuit-breakers, an algorithm has been developed (Figure 1).

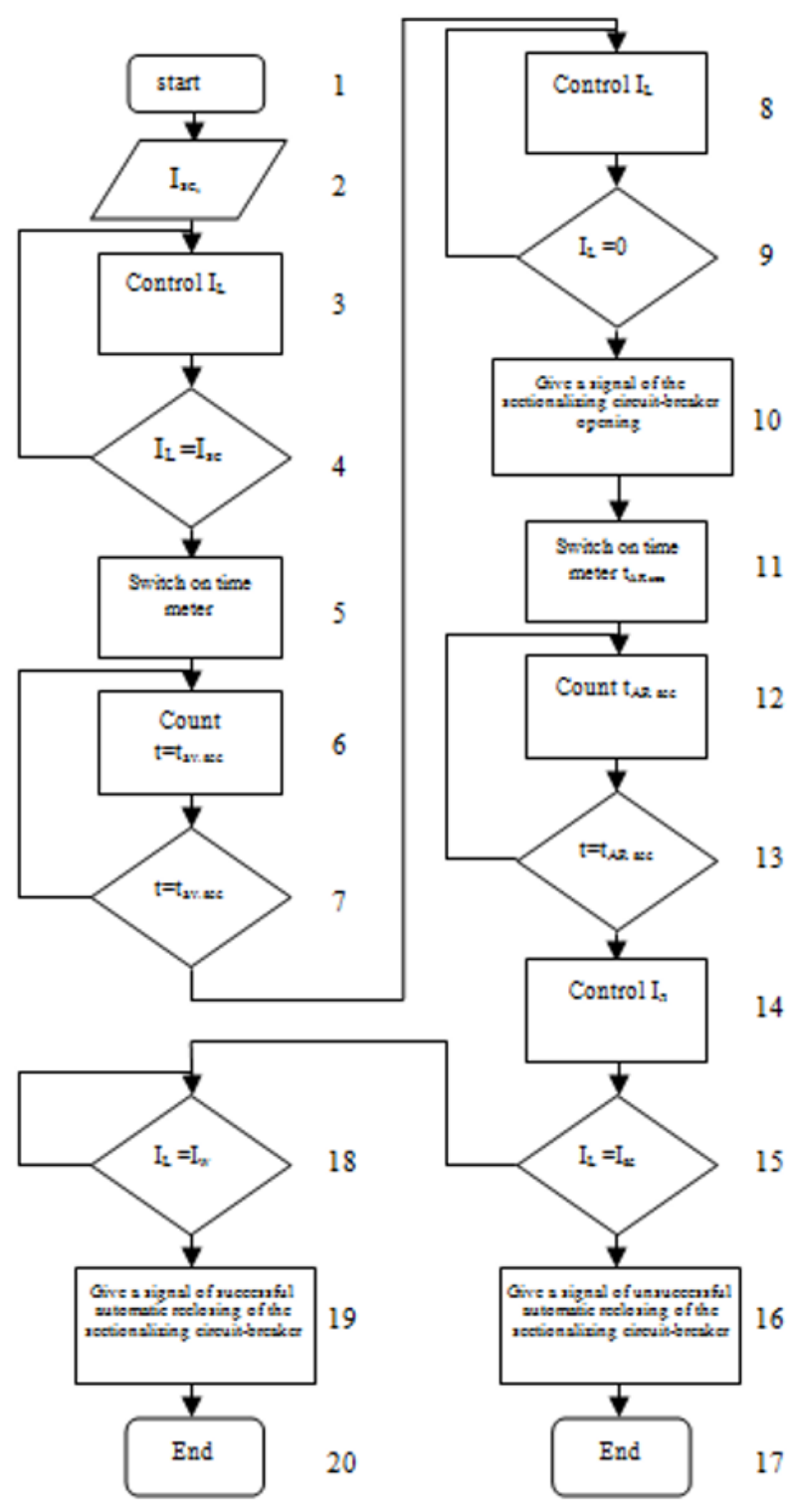

Fig. 1. Algorithm for implementing remote control of successful and unsuccessful automatic reclosing of sectionalizing circuit-breakers.

\section{Technical implementation}

The proposed algorithm is implemented in a device for remote control of automatic reclosing of sectionalizing circuit-breakers based on an analog-to-digital converter, with subsequent software-based processing of the received data on a computer.

Structurally, it consists of two units interconnected by a communication cable [13]. The first of the units, the current sensor connection unit, is designed to be connected to the line circuit. The second unit is used to convert and analyze the input signal, as well as to generate and transmit digital data to a PC for further analysis (information processing unit). Factually, the information processing unit (Figure 2) is the main part of the remote control device, since it not only generates data with the appropriate parameters, but also performs more complex logical functions, including the implementation of the proposed control methods.

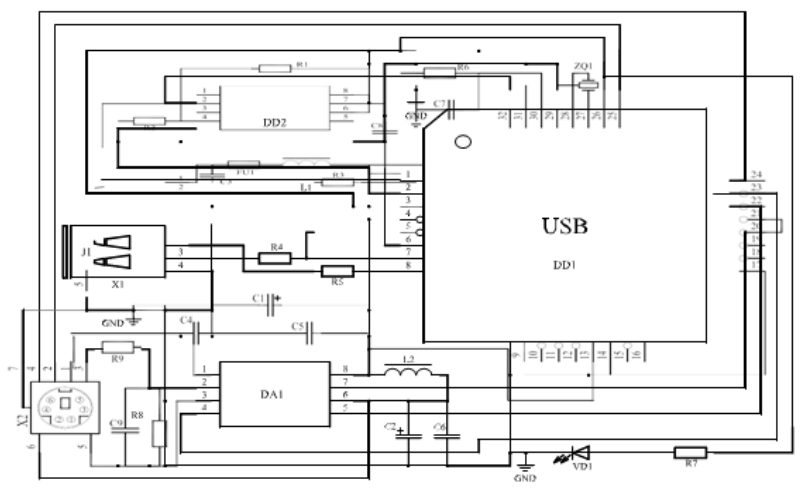

Fig. 2. Electrical circuit diagram of the IPU (Information Processing Unit): C1- C9 - capacitors; R1- R9 -resistors; VD1 - light-emitting diode; L1, L2 - chokes; DD1 - chip FT232BL; DD2 - chip M93C66-WDW6TP; DA1 - chip AD7495ARZ; ZQ1 - quartz; FU1 - fuse; X1 - connector USBB-1J; X2 connector MD6F; GND - "ground".

The information processing unit is a module that converts a signal from the current sensor unit (CSU) to the data supplied to the USB input of a PC for softwarebased processing and displaying the received data on a PC. The core of the module is three chips: FT232BL (controller-converter USB), M93C66-WDW6TP (programmable memory chip EEPROM), AD7495ARZ (analog-to-digital converter).

The signal from the current sensor unit [14] is fed to the input connector MD6F of the module. From there, it comes to the chips FT232BL and AD7495ARZ. The chip M93C66-WDW6TP is programmed in the manufacture of this device and, in general, can later be reprogrammed using a special programmer [15]. The chip is powered by a voltage of $5 \mathrm{~V}$ removed from the $\mathrm{L} 1$ choke.

\section{Conclusions}

1. Identified signs that allow to distinguish between situations of successful and unsuccessful automatic reclosing of sectionalizing circuit-breakers in sectionalized power lines allowed developing new methods of remote control.

2. An algorithm for implementing the proposed remote control methods has been developed.

3. The performed artificial short circuits fully confirm the operability of the developed technical means of the remote control device.

4. The implementation of the proposed methods will lead to improvement of power supply reliability of consumers by making the necessary decisions on the basis of the information received by the operational staff. 


\section{References}

[1] L.D. Surov, I.N. Fomin, Control of Unsuccessful Automatic Reclosing of the Sectionalizing Circuit-Breaker ELECTRO 6, 46- 8 (2009)

[2] I.N. Fomin, Belikov R. P. Algorithm for Remote Control of the Head Switch Line Bulletin of Orel State Agrarian University 61(4), $72-7$ (2016)

[3] E.I. Gracheva, O.V. Naumov, Estimation of power losses in electric devices of the electrotechnical complex, 2019 International Conference on Industrial Engineering, Applications and Manufacturing, ICIEAM 2019, 8742923 (2019)

[4] E.I. Gracheva, I.V. Ivshin, A.N. Alimova, Systematic Analysis of the Efficiency of Low-Voltage Switching Devices 2018 14th International ScientificTechnical Conference on Actual Problems of Electronic Instrument Engineering, APEIE 2018 - Proceedings, 8545897, 124-128 (2018)

[5] E.I. Gracheva, O.V. Naumov, Evaluation criteria of contact group technical state concerning electrical appliances, International Journal of Pharmacy and Technology, 8(4), 26763-26770 (2016)

[6] V.P. Mushchanov, A.N. Orzhekhovskii, A.V. Zubenko, S.A. Fomenko, Refined methods for calculating and designing engineering structures, Magazine of Civil Engineering, 78(2), 101-115 (2018)

[7] L.D. Surov, I.N. Fomin, Patent No. 2305356 Russian Federation IPC H02 J 13/00. Control Method of Successful and Unsuccessful Automatic Reclosing of Switches in a Sectionalized Line of a Ring Network. Applicant and patent holder FSEE HPE Orel State Agrarian University 2006118486/09, declare May 29, 2006, publ. 27.08.2007, bul. 24, 13 (2007)

[8] L.D. Surov, I.N. Fomin, V.F. Shumarin, Patent No. 2337453 Russian Federation IPC H02 J 13/00. The Control Method of the Shutdown and Successful Automatic Reclosing of the Sectionalizing Circuit-Breaker in the Ring Network Line Applicant and patent holder FSEE HPE Orel State Agrarian University №2007139420/09, declare 23.10.2007, publ. 27.10.2008, bul. 30, 7 (2007)

[9] L.D. Surov, I.N. Fomin, N.V Makhiyanova, Patent No. 2304338 Russian Federation IPC H02 J 13/00. The Control Method of the Shutdown and Unsuccessful Automatic Reclosing of the Sectionalizing Circuit-Breaker in the Ring Network Line Applicant and patent holder FSEE HPE Orel State Agrarian University №200611881/09, declare 24.04.2006, publ. 10.08.2007, bul. 22, 7 (2007)

[10] L.D. Surov, I.N. Fomin, Control Failure of Automatic Reclosing of the Sectionalizing CircuitBreaker ELEKTRO. Electrical Engineering, Electricity, Power Engineering. 6, 46-48 (2009)

[11] L.D. Surov, V.V. Filippov, The Control of Disconnection and Failure of Automatic Reclosing of the Main Switch of Line The Bulletin of Volgograd State Technical University Vol. 11, 8(135), 88-91 (2014)

[12] L.D. Surov, I.N. Fomin, N.V. Makhianova, Method of Control of Disconnection and Failure of Automatic Reclosing of the Sectionalizing Circuit-
Breaker in the Ring Network Line Patent of Russia No. 2304338. 2007. Bull. 22, (2007)

[13] L.D. Surov, V.V. Filippov, Determination of the Damaged Section of the Ring Network Line Bulletin of the Volgograd State Technical University 8(187), 105-10 (2016)

[14] N.S. Sorokin, Using of the Integrated Circuit FT232R Chip AD7495AR and in a Block of Digital Processing in the System to Control the Operation of Electrical Networks 6-35 kV Bulletin of Orel State Agrarian University 60(3), 87-93 (2016)

[15] N.S. Sorokin, Improving the Efficiency of Functioning of Electric Networks with Voltage of 6-35 $\mathrm{kV}$ by Monitoring the Parameters of the Electric Network Scientific Bulletin of the National University of Bioresources and Environmental Management Ukraine. Series: Technique and Power Engineering of AgroIndustrial Complex 209(2), 92- 95 (2015)

[16] V.A. Chernyshov, E.A. Pechagin, The Remote Control of Overhead Transmission Lines with Insulated Neutral Energy Conservation and Efficiency in Technical Systems, Proceedings of the IV Int. ScientificTechnical Conf. of Students, Young Scientists and Specialists (Tambov State Technical University) 355356 (2017) 